\section{O PLANEJAMENTO TERRITORIAL DO MUNICÍPIO DE SANTO AMARO DA IMPERATRIZ NA RM DA GRANDE FLORIANÓPOLIS COM A URBANIZAÇÃO DE ÁREAS RURAIS E O MANANCIAL DE ÁGUA}

\author{
The territorial planning of the municipality of \\ Santo Amaro da Imperatriz in RM of Grande \\ Florianópolis with the urbanization of \\ rural areas and the water source
}

http://doi.org/10.17648/ revistaterritorialidades-v1n2-4
Karina Martins da Cruz Universidade do Extremo Sul Catarinens

E-mail: karina.cruz@edu.udesc.br Orcid: orcid.org/0000-0002-7519-1484

Isa de Oliveira Rochata Instituto Federal de Santa Catariná

E-mail: mmoreira@ifsc.edu.br Orcid: orcid.org/0000-0002-9677-9578 Márcio Ricardo Teixeira Moreira Universidade do Estado de Santa Catarina

E-mail: isa.rocha@udesc.br

Orcid: orcid.org/0000-0001-9840-0595

\section{RESUMO}

Santo Amaro da Imperatriz (23.245 habitantes, estimativa IBGE 2019) é um município situado na Região Metropolitana da Grande Florianópolis (SC), integrando-se ao aglomerado urbano devido ao processo de conurbação com o município de Palhoça, principalmente ao longo da rodovia BR282, o que repercute na valorização de terras. Participam cerca de 1.000 famílias das atividades agrícolas e no seu território municipal está o maior manancial de água que abastece grande parte da Região Metropolitana. O novo Plano Diretor apresenta, no zoneamento, que as áreas agrícolas da planície aluvial sejam urbanizadas, deslocando-as para as fronteiras com o Parque Estadual da Serra do Tabuleiro. O artigo pretende discutir as transformações recentes do meio rural, o tipo de urbanização prevista, o manancial de água, as características da população e as atividades econômicas locais. Com o lento crescimento vegetativo, identifica-se a "urbanização extensiva" (BRENNER, 2018), na qual a expansão de construções é maior do que a necessidade da população pelo seu avanço sobre municípios com predomínios rurais e ambientais que apresentam funções de abastecimento nas bordas de uma região metropolitana. Além da revisão de literatura, efetuou-se a coleta de dados e informações no relatório de consulta pública do Plano Diretor Participativo (2019). Como resultado da pesquisa, destaca-se que os grupos empresariais buscam manter a sustentação de suas atividades por meio da existência de partições entre as instâncias de fiscalização, tentando fragilizar os encaminhamentos da legislação municipal.

Palavras-chave: Aglomerado urbano de Florianópolis. Urbanização. Áreas rurais. Plano Diretor. Manancial de água.
ABSTRACT

Santo Amaro da Imperatriz (23,245 inhabitants, estimate IBGE 2019) is a municipality located in the Metropolitan Region of Greater Florianópolis (SC), integrating itself into the urban agglomeration due to the conurbation process with the municipality of Palhoça, mainly along the BR-282, which affects the valuation of land. About 1,000 families participate in agricultural activities and in its municipal territory is the largest source of water that supplies much of the Metropolitan Region. The new Master Plan presents in the zoning that the agricultural areas of the floodplain are urbanized, moving them to the borders with the Serra do Tabuleiro State Park. The article intends to discuss the recent transformations of the rural environment, the type of urbanization planned, the water source, the characteristics of the population and the local economic activities. With the slow vegetative growth, "extensive urbanization" is identified (BRENNER, 2018), in which the expansion of buildings is greater than the population's need for its advance over municipalities with rural and environmental predominance that have supply functions in the cities edges of a metropolitan region. In addition to the literature review, data and information were collected in the public consultation report of the participatory Master Plan (2019). As a result of the research, it is highlighted that the business groups seek to maintain the sustainability of their activities through the existence of partitions between the inspection bodies, trying to weaken the referrals of the municipal legislation.

Keywords: Florianópolis urban cluster. Urbanization. Rural areas. Master plan. Water source. 


\section{INTRODUÇÃO}

Santo Amaro da Imperatriz é um município distante cerca de $25 \mathrm{~km}$ da capital catarinense (Florianópolis) e caracteriza-se pela produção hortifrutigranjeira em pequenas propriedades familiares, comportando em seu território o maior manancial de água para abastecimento da Região Metropolitana da Grande Florianópolis, os rios Cubatão do Sul e Vargem do Braço. Estima-se que a população esteja em torno de 23.245 habitantes (INSTITUTO BRASILEIRO DE GEOGRAFIA E ESTATÍSTICA, 2019), sendo que o crescimento populacional vem aumentando de 15 a $17 \%$ a cada década, entre 1991 e 2010.

A expansão urbana de Florianópolis promoveu esta equação entre áreas mais urbanizadas nos seus limites e o baixo grau de urbanização nos municípios interioranos da sua região. Nesta faixa de localidades de baixo grau de urbanização encontram-se municípios que, historicamente originados de antigas colônias de povoamento alemãs do século XIX, abasteceram Florianópolis com gêneros alimentícios diversos. ${ }^{2} \mathrm{Na}$ fachada litorânea próxima a Florianópolis, conduziam produtos artesanais das comunidades continentais próximas (São José, Biguaçú e Palhoça), além da produção agrícola, queijos, salames, etc., que chegavam das áreas coloniais interioranas da região. Tal fluxo de abastecimento permanece e se adapta ao rodoviarismo, principalmente a partir da pavimentação das BR-101 e BR-282 nas décadas de 1970 e1980, respectivamente.

Atualmente, o estado de Santa Catarina possui elevado saldo migratório que "não dá indícios de arrefecimento" (CARMO; CAMARGO, 2018, p.78) eSanto Amaro da Imperatriz está se constituindo em um espraiamento ${ }^{3}$ urban sprawl) do aglomerado urbano de Florianópolis (vide Figura 1), devido à contiguidade com a cidade média de Palhoça e ao movimento rodoviário da BR-282 e BR-101. Com isso, o valor da terra também passa a se alterar. Mais da metade da área total municipal de Santo Amaro da Imperatriz está dentro do limite formal do Parque Estadual da Serra do Tabuleiro, ou seja, áreas de proteção que não podem ser ocupadas (58,11\% da área do município), o que repercute em uma pressão das áreas agrícolas para se tornarem urbanizadas.

$\mathrm{Na}$ análise dos censos demográficos (de 1990 a 2010), a partir do ano de 2000, a proporção de moradores em áreas rurais e urbanas se estabilizou em consequência do Plano Diretor anterior ao Estatuto das Cidades (Lei Ordinária n 890/1991), a partir do qual foram estabelecidas as áreas de plantio e pastagem dentro do perímetro urbano municipal, situadas às margens do rio Cubatão do Sul, limitando-as à concentração urbana de Santo Amaro da Imperatriz. Além disso, pela Lei Ordinária n 1194/1998, foi alterado o valor genérico das áreas rurais, chegando a uma redução de até $200 \%$ no preço atribuído às terras, para possibilitar o acesso de terras às atividades agrícolas. Assim, as áreas com produção rural passaram a estar dentro da área urbana.

A ocupação urbana ocorre na estreita faixa de planície margeando o rio Cubatão do Sul e seus afluentes, classificando o relevo como Colinas, Morros Altos e Morros Baixos. ${ }^{5}$ A variação

\footnotetext{
${ }^{1}$ A população urbana perfaz 7.701 (1991), 12.536 (2000), 14.970 (2010), enquanto a população rural apresenta 6.157 (1991), 3.918 (2000) e 4.853 (2010) nos censos demográficos, totalizando 13.858 (1991), 16.454 (2000) e 19.823 (2010) (Atlas do Desenvolvimento Humano no Brasil, 2013).

2 Além de Santo Amaro da Imperatriz, são também municípios que se formaram de núcleos populacionais oriundos das colônias alemãs na Região Metropolitana da Grande Florianópolis, com as suas respectivas estimativas populacionais (em número de habitantes): São Pedro de Alcântara (5.823), Antônio Carlos (8.513), Águas Mornas (6.469), Rancho Queimado (2.878), Angelina (4.801), São Bonifácio (2.838) e Anitápolis (3.232) (IBGE, 2019).

${ }^{3}$ Refere-se o espraiamento à expansão horizontal na região metropolitana, antes de aumentar a densidade populacional nas áreas já consolidadas das cidades urbanas. Desse modo, configuram-se as cidades-dormitório, nas quais ocorre uma divisão territorial do trabalho em que os moradores se deslocam para as cidades centrais em busca de melhores salários.

${ }^{4}$ De acordo com o Instituto do Meio Ambiente de Santa Catarina (IMA/SC).

${ }^{5}$ Conforme a classificação de método do Conselho de Pesquisas e Recursos Minerais (CPRM).
} 
Figura 1 - Região Metropolitana da Grande Florianópolis e o seu aglomerado urbano
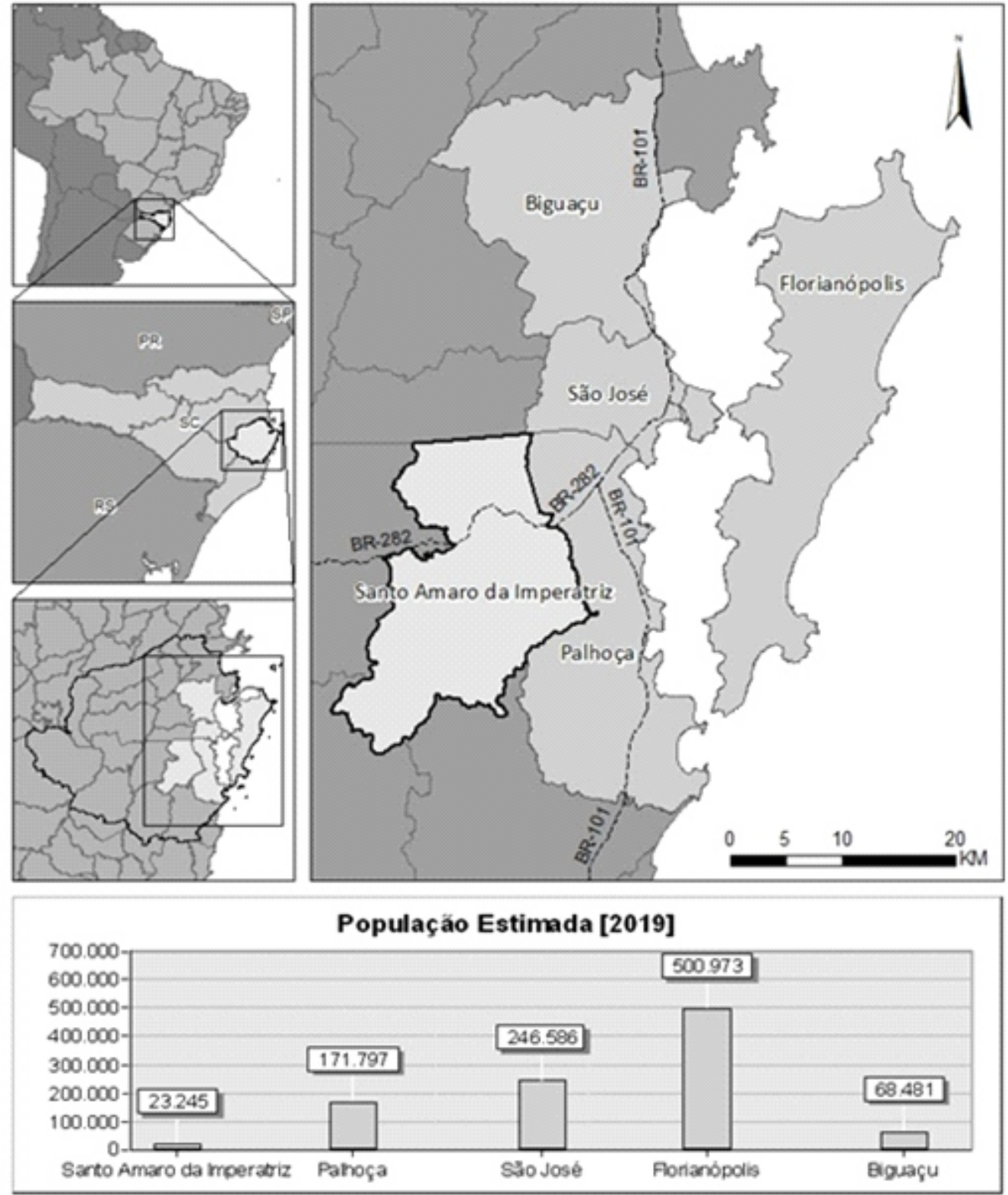

Fonte: Vetorial: IBGE - Dados Populacionais IBGE Cidades Elaboração: João Daniel Barbosa Martins 2019.

de altitude, em relação ao nível do mar, é de 20 a 1.200 metros, sendo grande parte Domínio das Serras do Leste Catarinense. A configuração da paisagem acidentada direciona naturalmente os assentamentos humanos "que se resumem da média encosta para jusante. As atividades de subsistência da população são a base da economia" (VEADO, 2014, p. 27), próximo do Parque Estadual da Serra do Tabuleiro.

A estrutura fundiária do município de Santo Amaro da Imperatriz vem sendo alterada nas localidades de planície aluvial (várzeas) em que se apresentam os gêneros da lavoura temporária e pastagens, além das residências dos seus proprietários. As atividades rurais possuem a tendência de serem substituídas pela especulação imobiliária, ou seja, pela expectativa de venda da terra, especialmente com o advento do Plano Diretor. ${ }^{6}$ As áreas de plantio e pastagens nas proximidades em que se estabelecem loteamentos, condomínios e

6 O novo Plano Diretor foi aprovado pela Lei Complementar nº 224, de 20 de dezembro de 2019. 
prédios recém-construídos, ao serem convertidas em área urbana com o consequente pagamento do Imposto Predial e Territorial Urbano (IPTU), inviabiliza a continuidade produtiva, em virtude da elevação dos custos de diversos gêneros agrícolas de menor preço que utilizam o sistema de rotação de culturas, diminuindo a diversificação agrícola. Apesar de Santo Amaro da Imperatriz apresentar uma arrecadação de IPTU considerada pouco expressiva (SILVA; SILVA; TEIXEIRA, 2018), dependendo de outras fontes, como o Fundo de Participação dos Municípios (FPM) e receitas tributárias, o imposto urbano apresentou significativo crescimento de $39,49 \%$ entre 2017 e 2018, e de $44,24 \%$ entre 2018 e 2019 .

O tipo de ocupação das terras em faixas, que antes eram exclusivamente de uso agrícola, caracteriza a agricultura familiar das pequenas propriedades. As atividades rurais, seja a rotação de culturas ou de pequenas a médias pastagens, significa uma renda principal ou complementar das atividades comerciais dos proprietários. São faixas extensas de glebas agricultáveis, circundadas por áreas que já estão sendo urbanizadas.

A incompatibilidade de unidades agrícolas com futuras atividades de comércio, prédios e loteamentos, por exemplo, gera uma problemática na organização do espaço, uma vez que as questões ambientais se agravam como mais aterros para construção, impermeabilização do solo, falta de escoamento da rede pluvial, ocupação das margens de rios e assoreamento, horários reduzidos na coleta de lixo, entulhos e contaminação do solo, desmatamento, deslocamento de espécies de aves e pequenos mamíferos silvestres, além de focos de animais exóticos como escorpiões e caramujos africanos nos bairros.

O valor aumentado da terra desocupada ou a especulação imobiliária inviabilizam tanto o cultivo quanto o pastoreio. As áreas para moradia se encontram em depósitos de planície de inundação fluvial, as quais são áreas aplainadas e situadas entre os cursos d'água, também características ideais para a agricultura? A exploração das atividades econômicas relacionadas com a extração de areia e argila nas margens do rio Cubatão do Sul ocasiona elevada turbidez e aumento nos custos com o tratamento da água para consumo (VEADO, 2014), realizado pela Companhia Catarinense de Águas e Saneamento (CASAN), que utiliza as águas dos rios Cubatão do Sul e Vargem do Braço para abastecer os municípios de Santo Amaro da Imperatriz, Palhoça, Florianópolis, São José e Biguaçú.

É necessário interpretar o planejamento territorial municipal, relacionando as transformações recentes no meio rural, o tipo de urbanização prevista, o manancial de água, as características da população e as atividades econômicas locais, para que a análise consiga demonstrar de que maneira está se desencadeando a urbanização no município de Santo Amaro da Imperatriz enquanto partícipe do aglomerado urbano de Florianópolis. O método utilizado é a pesquisa explicativa, buscando realizar conexões entre ideias e fatores identificados, a fim de compreender as causas e efeitos ao tentar explicitar a ocupação urbana que está em curso. A coleta de dados está baseada no estudo experimental de um formulário de consulta pública do Plano Diretor Participativo, extraindo dados quantitativos e qualitativos para entender as manifestações da sociedade e estruturar os possíveis apontamentos.

\section{A URBANIZAÇÃO DE ÁREAS RURAIS}

Santos (1993) salienta que as cidades utilizam parte dos terrenos agrícolas vazios dentro da aglomeração nas regiões metropolitanas brasileiras, caracterizando os municípios menores

\footnotetext{
7 É importante notar que a arrecadação do IPTU vem crescendo nos últimos anos: R\$ 959.723,49 em 2014; R\$ 1.357.270,20 em 2015; R \$ 1.431.799,94 em 2016; R \$ 1.834.995,02 em 2017; R\$2.559.798,96 em 2018, e R \$ 3.692.403,97 em 2019 (TRIBUNAL DE CONTAS DO ESTADO DESANTA CATARINA, 2020).

8 Os cursos d'água representam $2.084 \mathrm{~km}$ de comprimento total na área de drenagem com $742 \mathrm{~km}^{2}$ da bacia hidrográfica do rio Cubatão do Sul (SECRETARIA DE ESTADO DO DESENVOLVIMENTO ECONÔMICO SUSTENTÁVEL DESANTA CATARINA, 2018).
} 
em áreas rurais adaptadas a demandas urbanas. É nos municípios mais urbanizados (Palhoça, São José, Florianópolis e Biguaçú) que os habitantes de Santo Amaro da Imperatriz trabalham, recebendo melhores salários e adquirindo os principais bens de consumo (simples e duráveis). Da outra parte, os moradores dedicados à sua base econômica, o setor primário, produzem os alimentos necessários à garantia da vida urbana em ligação comercial com a CEASA, situada em São José. A água para consumo, que é tratada pela CASAN dentro de Santo Amaro da Imperatriz, também pode ser considerada nessa relação de troca. O que diferencia uma região urbana de uma região agrícola em uma relação de cooperação, segundo Santos (1985) não é a especialização funcional, mas a quantidade, a densidade e a multidimensão, ou seja, fatores de escala entre produção e consumo. O efeito de contiguidade entre Palhoça e Santo Amaro da Imperatriz torna este último município, uma "nova região urbana" por conta da urbanização acelerada da cidade média vizinha.

O urbano reproduz-se, de forma "espontânea" pelo "livre jogo do mercado", especialmente sob a lógica da urbanização metropolitana, e, por outro lado, "planejada" no intento das instituições públicas em produzirem a infraestrutura e a criação de leis de zoneamento (CARLOS, 1994, p.189). A modernização agrícola nos pequenos lotes possibilitou a rotação de culturas em menos tempo de produção com o uso intensivo de agrotóxicos para aumentar a rentabilidade. Mas, estes mesmos pequenos lotes podem ser facilmente convertidos em terrenos para residência ou comércio e serviços, sabendo-se que as áreas agrícolas mais produtivas estão dentro do perímetro urbano municipal, nos quais tanto as glebas como a demanda predial acabam recebendo um preço artificial. A posse e o controle do uso das terras urbanas constituem condições de viabilização das estratégias de alguns grupos empresariais, sejam famílias proprietárias de terras, incorporadoras e construtoras locais.

A própria modernização agrícola, de acordo com Santos (1993), proporciona que o consumo consuntivo (que não retorna às atividades produtivas) amplie-se entre os lugares de produção agrícola e as áreas urbanas, com a criação de uma demanda heterogênea, conforme as faixas de renda, o que permite a reprodução da arquitetura urbana,contribuindo, assim, para ampliar a escala da urbanização, para fortalecer tanto a diferença demográfica quanto a divisão regional do trabalho.

Em Santo Amaro da Imperatriz, a estratificação da renda da população passa a definir os tipos de ocupação urbana. A expectativa em torno do Plano Diretor vem gerando: a) processo especulativo no valor elevado dos novos apartamentos de edifícios centrais; b) ocorrência marcante de prédios com quitinetes disponibilizadas para locação a novos moradores; c) aumento de pequenas residências à venda nos bairros periféricos ao núcleo central; d) fracionamento de áreas agrícolas para loteamentos clandestinos através de servidões de passagem ao lado das plantações; e) algumas áreas de pastagem maiores se tornando condomínios fechados de classe média alta; f) ocupação dos morros em áreas de nascentes e vegetação.

Rangel (2005, p. 112) entende que tanto a demanda agrícola quanto a demanda predial tenderiam a declinar por causa das inovações tecnológicas. A demanda agrícola por terras declina por causa da elevação da produtividade (os insumos) por unidade de área. A demanda predial por terras também pode declinar em função das novas técnicas de construção (com o aumento da densidade de ocupação residencial). Então, é necessária outra demanda de terra, causadora da valorização da terra rural e também urbana: a "quarta renda". Com a quarta renda, segundo Rangel (2005), o preço da terra será inverso ao da taxa de lucro da renda territorial. Assim, se o lucro da terra é pequeno, muitas vezes, o preço da terra se eleva. O movimento de elevação do preço da terra leva a uma "expectativa de subsequente elevação". O preço da terra passará a comportar-se como se ele próprio fosse uma renda. A ascensão do preço da terra cria um ciclo próprio de crescimento. Então, nos períodos recessivos, ocorre a elevação no preço da terra.

\footnotetext{
${ }^{9}$ Centrais de Abastecimento do Estado de Santa Catarina.
} 
Tal expectativa de aumento no valor da terra, ano a ano, após a queda na taxa de lucro ou mesmo a sua estagnação durante o período recessivo, torna o meio rural instável, com a terra passando a ser um objeto especulativo, causando fragilidade no sistema de produção agrícola. A pequena propriedade rural apresenta uma limitação de lucro, conforme o tamanho da gleba, preço dos insumos e valor da safra. Assim, nota-se que a quarta renda ocasiona a alteração na cadeia produtiva regional. Com o lucro limitado e o nível de vida da população permanecendo baixo, a expulsão dos produtores rurais leva a migrações, chamadas por Singer $(2002$, p. 37) de "fatores de estagnação", que se manifestam devido à crescente pressão demográfica sobre a disposição de áreas cultiváveis, seja limitada pela insuficiência de terra propícia à agricultura ou pela monopolização de grande parte das terras nas mãos de alguns proprietários.

Participam das atividades agrícolas e pastagem de pequena propriedade cerca de 1.000 famílias em Santo Amaro da Imperatriz. ${ }^{10}$ Lefebvre (1978) entende que, na comunidade campesina, predominam os vínculos de consanguinidade que, quando se dissolvem, deixam vínculos na territorialidade, fundados na residência, na riqueza, no prestígio, na propriedade ena autoridade. A religiosidade também é uma forma ideológica de coesão social nas áreas rurais.

A terra excedente das famílias de agricultores está passando a ser objeto de interesse de um mercado imobiliário local que vem se formando em função do crescimento populacional do aglomerado urbano de Florianópolis. A demanda habitacional acaba requerendo mais áreas com preços acessíveis para assentamentos. Com isso, os pequenos agricultores constroem pequenos prédios para aluguel de quitinetes nos terrenos anteriormente agrícolas próximos ao núcleo central, além da abertura de servidões de passagem, aproveitando as estradas em que entravam as máquinas nas plantações mais amplas, para receber novas casas sem arruamento, esgoto e fiação elétrica compatível. De outro lado, é crescente a intensificação de ações do mercado imobiliário, atento à demanda da classe média alta, investindo em prédios, loteamentos e condomínios fechados dentro e fora do perímetro urbano. As famílias de comerciantes locais e construtoras de outros municípios realizam parcerias, e, assim, interferem nos zoneamentos previstos no Plano Diretor.

As alterações nas formas de propriedade entre o campo e a cidade acompanham conflitos, desde a propriedade fundiária até as propriedades corporativas e capitalistas (LEFEBVRE, 2004). Em Santo Amaro da Imperatriz, identifica-se um mercado imobiliário informal por meio dos prédios de quitinetes, e do parcelamento e venda de lotes sem a submissão da aprovação na Prefeitura e, do outro lado, um mercado imobiliário especulativo nos valores de apartamentos e lotes de alto padrão. Em função da procura por terrenos para construção, este processo atraiu a atenção de diversos agentes, inclusive de políticos, promovendo ações para a legalização das servidões e regularização dos contratos particulares de compra e venda, ou das escrituras públicas no parcelamento de condomínios horizontais.

\section{INTERESSES MANIFESTADOS NO PLANO DIRETOR}

O Plano Diretor Participativo organiza-se na leitura da realidade (um diagnóstico), compilação do documento e condução dos trabalhos pela equipe técnica; representações comunitárias e setoriais que se reuniram nos bairros acompanhados por um núcleo gestor de caráter consultivo; e pela consulta pública apreciada em audiências públicas para decidir os pontos finais das determinações previstas para o planejamento urbano municipal. As consultas públicas reúnem 82 formulários, ${ }^{11}$ dentre 67 realizados de forma online e 15 impressos que foram

\footnotetext{
${ }^{10}$ Informação verbal obtida no Sindicato dos Trabalhadores Rurais de Santo Amaro da Imperatriz. Santo Amaro da Imperatriz, 31/07/2019.

11 Dentre os 82 pedidos, dois deles foram "testes" na forma online realizados pela equipe técnica. Portanto, são válidos 80 pedidos no documento chamado "Relatório de Contribuições Recebidas no período de Consulta Pública", disponível a consulta pública entre 22 de agosto a 20 de setembro de 2019, aberta a qualquer morador ou não do Município(PMSAI, 2019).
} 
entregues na Prefeitura. ${ }^{12}$ As consultas públicas podem demonstrar as instâncias conflitivas e os interesses encrustados nos pedidos de inclusão, exclusão ou alteração para a versão final do Plano Diretor, antes da apreciação na Câmara Municipal de Vereadores.

A participação individual contou com $36,25 \%$ dos formulários encaminhados. As representações de entidades foram a maioria das intervenções $(63,75 \%)$, tendo como as principais, em quantidade, SECOVI/SC (28,75\%), UNISULDORIO (12,5\%) e Equipe Técnica do Plano Diretor $(7,5 \%)$, e os representantes da Prefeitura Municipal, Câmara de Vereadores de Santo Amaro da Imperatriz e OAB de Palhoça, somados, resultando em 15,68\% das manifestações de entidades. ${ }^{13}$ Outras duas entidades aparecem, em formulários separados, porém, contendo várias observações sobre as partes do Plano Diretor: Associação dos Mineradores de Areia da Bacia do Cubatão e a Associação de Moradores do Bairro Fabrício (AMFA). Nas contribuições recebidas, constam apenas duas associações de moradores e um abaixo assinado de moradores situados em uma rua central de recente interesse imobiliário, que é considerado, na pesquisa, como uma entidade por representar interesses coletivos.

No tocante aos dispositivos contidos na redação do Plano Diretor, os formulários se referem à alteração $(46,25 \%)$, inclusão $(33,75 \%)$ e exclusão $(20 \%)$. Os pedidos de "alteração" foram realizados, na maior parte, por entidades $(62,16 \%)$; nos pedidos de "inclusão" ocorreu equivalência entre entidades e pessoas individuais - a UNISULDORIO é a entidade com maior participação; e os pedidos de "exclusão" foram realizados somente pelos representantes do SECOVI/SC e Associação dos Mineradores de Areia da Bacia do Cubatão.

Dada a frequência pela contagem numérica dos formulários sobre os "dispositivos destacados" relativos às partes do Plano Diretor, alguns apontamentos se tornam possíveis para discussão com o resultado da votação em audiência pública ${ }^{14}$, a fim de compreender a respectiva colocação na versão final.

Sobre as diretrizes do Plano Diretor, o artigo 11, no inciso XIII, consta o licenciamento de obra ou atividade potencialmente causadora de significativa degradação por meio dos estudos de impacto ambiental e de vizinhança. Os representantes do SECOVI/SC e da Associação de Mineradores de Areia da Bacia do Cubatão realizaram pedido de exclusão deste inciso, alegando que a mineração, por exemplo, é da instância fiscalizadora do IMA/SC. No Plano Diretor foi mantida a redação em reconhecimento à Lei.

A Associação de Mineradores solicitou a exclusão dos seguintes artigos: o artigo 87 que é relacionado às áreas de risco entendidas como as naturais e aquelas provocadas pelos efeitos danosos do solo; os artigos 392, 394 e 396 referentes às áreas especiais de interesse de proteção do salto do rio Cubatão A, B e C, proibindo nelas a extração de areia, a expansão e ocupação urbana, com o incentivo às iniciativas de preservação ambiental. O referido artigo 87 sofreu alteração na sua redação, especificando-se que são consideradas áreas de risco aquelas que causem danos à saúde, à integridade física e à propriedade. Sobre os artigos 392, 394 e 396, decidiu-se que o resguardo destas áreas, para interesses de preservação e do turismo, caracteriza as votações nas oficinas comunitárias realizadas na construção do Plano Diretor, no que cabe ao Município dirimir conflitos e primar pela economia e o desenvolvimento sustentável.

São relevantes, para os representantes do SECOVI/SC e da Associação de Mineradores, os pedidos de exclusão do artigo 549 , especialmente, o inciso $\mathrm{V}$, referente às competências do Conselho da Cidade de Santo Amaro da Imperatriz, as quais foram votadas e mantidas as funções de acompanhar, opinar e avaliar medidas mitigadoras de impactos ambientais. Ocorreu interesse

12 As manifestações apresentam a identificação de autoria, compiladas em tabelas e recebendo número único de protocolo, exceto um encaminhamento (igual ao formulário entregue em mãos).

13 Leia-se Sindicato das Empresas de Compra, Venda, Locação, Administração de Imóveis e dos Condomínios Residenciais e Comerciais de Santa Catarina (SECOVI); Associação de Moradores do Sul do Rio (UNISULDORIO);

14 Ordem dos Advogados do Brasil (OAB) de Palhoça.

No "Relatório da Conferência Final do Plano Diretor Participativo de Santo Amaro da Imperatriz", de novembro de 2019, estão compiladas as decisões e o resultado das votações nas audiências públicas em apreciação às contribuições do período da consulta pública (PMSAI, 2019).

Revista Territorialidades, Salvador, v. 1, n. 2, p. 40-51, jul./dez. 2020 
pela exclusão do artigo 449, para SECOVI/SC e OAB de Palhoça, que trata sobre a parcela do solo urbano para fins de condomínios para ser considerado como regular. A nova redação acabou implicando na desobrigação de reconhecimento, da Administração Pública, quanto à legitimidade do terreno, aceito apenas o domínio útil ou posse do terreno para construção, passando a integrar o artigo 550. Dessa forma, foi aberta uma lacuna para que aconteçam processos especulativos antes da regularização dos terrenos.

A intervenção de um representante da Câmara Municipal é percebida nos pedidos de alteração, sobre o zoneamento, referindo-se às áreas para fins turísticos, industriais e habitacionais em áreas rurais. Pede-se, inclusive, a permissão de 8 pavimentos para que um hotel seja instalado no Morro dos Ventura, local em que existe um único acesso viário íngreme com pista simples, ruas estreitas e parcialmente pavimentadas.

Destaca-se, entre a participação das pessoas individuais, a discussão sobre as áreas de transição entre as áreas rurais e urbanas, pedidos de aumento no tamanho dos lotes, tanto nas áreas rurais como nas áreas centrais, a fim de evitar o adensamento habitacional. Há grande frequência nos pedidos de aumento de pavimentos ou a sua limitação, condicionados ao sistema viário, esgotamento sanitário e escolas nas proximidades.

A UNISULDORIO reivindica, pontualmente, na redação de alguns artigos, a preocupação com o impacto de vizinhança e a mobilidade urbana. O bairro Fabrício, por meio do representante da AMFA, pede tratamento igual aos outros bairros, em observação aos artigos 367 a 372, tratando sobre infraestrutura urbana, áreas de inundação, vias de acesso, e uso e parcelamento do solo, nas chamadas "zonas de qualificação e estruturação urbana" e "áreas de especial interesse". O representante do abaixo assinado de moradores situados em uma rua central, sob um recente processo de verticalização por meio de prédios novos em construção, pede a limitação no número de pavimentos para que o trânsito de veículos seja estabilizado.

É importante notar, dentre as intervenções apresentadas, que, nos artigos de interesses coletivos, é que são abertas brechas nas quais alguns grupos empresariais, como forma de não terem suas atuações obstruídas, procuram, juridicamente, manter a sustentação de suas atividades por meio da existência de partições entre as instâncias de fiscalização, tentando fragilizar os encaminhamentos da legislação municipal. Alguns prédios foram embargados no ano anterior ao processo de elaboração do Plano Diretor, o que também colocou em suspeição os interesses especulativos, que tiveram de buscar outros terrenos para promover a expansão do interesse empresarial sobre o Município.

\section{O MANANCIAL DA ÁGUA}

O zoneamento do novo Plano Diretor não especifica a necessidade de preservação das margens dos rios ${ }^{15}$ e retira a função agropastoril produtiva de diversas áreas. O macrozoneamento apresenta oito zonas urbanas, situadas desde o Canto da Amizade (área de expansão habitacional isolada, próxima ao município de Águas Mornas), passando pelo núcleo central, até as extensas áreas de várzeas no bairro Sul do Rio, onde as características econômicas são essencialmente agrícolas e de pastagem.

É importante destacar que o Parque Estadual da Serra do Tabuleiro apresenta zonas de amortecimento caracterizadas por uma faixa contínua de 500 metros que contorna toda a extensão da área da UC, para diminuição de possíveis conflitos ambientais (PELLERIN, 2011). As zonas de amortecimento encontram-se sem reconhecimento pelo Plano Diretor, apesar de o Plano de Manejo do Parque ter sido aprovado em 2019. O zoneamento do Plano Diretor está definindo as áreas lindeiras ao Parque como novas áreas de expansão agrícola.

\footnotetext{
${ }^{15}$ Na Lei Ordinária n 890/1991, o primeiro Plano Diretor Municipal, havia a zona de margens de águas públicas (ZMAP).
} 
Em que pesem as áreas agrícolas como predominantes, o Plano Diretor prevê que extensas faixas na planície aluvial marginais ao rio Cubatão do Sul sejam consideradas como "macrozona urbana", a fim de delimitar o novo perímetro urbano municipal. A generalização da ocupação urbana na planície aluvial compromete os recursos hídricos pelos efluentes domésticos, industriais, agrícolas e hospitalares.

Além do abastecimento público, outras atividades econômicas dependem da recarga de água na bacia hidrográfica, tais como: envasamento de água mineral, fábricas de sorvete, fábricas de gelo, cervejarias, cachaçarias artesanais, aquicultura, agricultura, cadeira produtiva de frigoríficos de médio porte, esportes de aventura nos rios e morros, hotéis de águas termais, asilos, hospital, espaços para eventos, algumas agroindústrias e outros tipos industriais de pequeno a médio porte.

Dentre os fatores que contribuem nas atividades agrícolas locais, está a diversificação no tamanho das propriedades, a disponibilidade de terrenos férteis nas várzeas e a água abundante para irrigação. A proximidade com Florianópolis repercute na necessidade da agricultura periurbana em municípios com pouca urbanização na região de entorno, sendo Santo Amaro da Imperatriz um dos seus principais fornecedores de alimentos vegetais frescos.

Os problemas mais evidentes da bacia hidrográfica do rio Cubatão do Sul são a turbidez da água, principalmente nos períodos chuvosos, que é ocasionada pelo desmatamento da mata ciliar, uso de defensivos agrícolas, saneamento básico insuficiente e a ocorrência de áreas de extração de areia e argila (VEADO, 2014). Há algumas décadas, é recorrente a falta de água encanada em determinados períodos do ano, em especial, relacionada aos meses de menor precipitação na bacia hidrográfica, de abril a agosto (FRANCESCHI; OLIVEIRA, 2017), no aglomerado urbano de Florianópolis. Parte desta problemática relaciona-se diretamente com a sobrecarga da retirada de água nesta bacia hidrográfica, que, em determinadas épocas fora da normalidade climática, possui vazão insuficiente às taxas de consumo (KAETSU, 2015). A falta de água vem sendo ocasionada por uma intensa estiagem a cada ano, afetando o abastecimento de Santo Amaro da Imperatriz, Palhoça, São José, Biguaçú e Florianópolis.

As características existentes no aglomerado urbano de Florianópolis, sob um tipo de urbanização guiado pela especulação imobiliária, contaminando e inutilizando as águas de boa parte dos rios locais para lazer, navegação e fonte de alimentos, levam a entender que as atividades agrícolas em Santo Amaro da Imperatriz, ao serem substituídas pelo uso e ocupação urbana, acompanhariam tais consequências nos seus rios e córregos. Já ocorre um conflito de interesses entre os mineradores que extraem areia e os agricultores que bombeiam as águas do rio Cubatão do Sul, bem como entre os praticantes e empresas de rafting com os mineradores de areia nas margens dos rios. Os contaminantes urbanos acentuados e a compactação do solo inviabilizariam tais atividades econômicas e a água para consumo.

Os limites do Parque Estadual da Serra do Tabuleiro reduzem em menos da metade a área de Santo Amaro da Imperatriz para ser habitada. Há, portanto, uma condicionante ambiental determinada para o seu crescimento urbano, enquanto o principal manancial de água para captação e abastecimento da região. As áreas agrícolas pressionadas na "macrozona urbana" para finalmente se tornarem urbanizadas ocasionam o comprometimento dos pequenos canais e cursos d'água, que, segundo Suguio e Bigarella (1990), facilitam na planície de inundação a entrada de água durante as enchentes e auxiliam a drenagem nas vazantes do rio.

No Comitê da Bacia Hidrográfica do Rio Cubatão do Sul, formado por representantes do governo estadual, da sociedade civil e de empresários locais, Kaetsu (2015) identificou-se uma limitação nas suas funções deliberativas devido ao atrelamento institucional e à restrição nas atividades técnico-administrativas. Nota-se que a densidade institucional está sob uma realidade em evolução e enquanto resultado simultâneo de "compromissos estáveis" e "jogos de poder" entre os atores sociais. 


\section{CONSIDERAÇÕES FINAIS}

As relações que se apresentam entre a conversão das áreas agrícolas produtivas em se tornarem zonas para expansão urbana, bem como as bordas do Parque Estadual da Serra do Tabuleiro em pastagens ou plantações, caracterizam o Plano Diretor como um instrumento normativo que não está centrado nas atividades agrícolas e nas áreas da unidade de conservação. Notadamente, a diretriz principal do Plano Diretor está na definição das novas áreas de crescimento urbano por meio de critérios que não observam a dimensão fluvial e seus desdobramentos para o Município e a região metropolitana em que está inserido.

Sabe-se da importância da participação hortifrutigranjeira de Santo Amaro da Imperatriz como município fornecedor à CEASA/SC e o peso de 1/3 do setor primário na economia municipal. Com o novo Plano Diretor, a alteração no tamanho e estrutura da população irá se expressar no território, transformando o uso e a cobertura do solo, especialmente, de áreas das atividades agrícolas para áreas urbanizadas na faixa oeste para leste das margens do rio Cubatão do Sul e de áreas de vegetação lindeiras ao Parque Estadual da Serra do Tabuleiro para novas áreas agrícolas na direção sul.

Com as alterações nos grupos etários adultos devido à chegada de novos moradores, é esperado, em longo prazo, um aumento na urbanização desconcentrada superior ao crescimento populacional. Esta expansão de construções, maior do que a necessidade da população, é denominada por Brenner (2018) de "urbanização extensiva", pelo seu avanço sobre os municípios com predomínios rurais e ambientais que apresentam funções de abastecimento nas bordas de uma região metropolitana. A chegada de novos moradores deve ampliar os núcleos familiares e, assim, de domicílios, ao contrário do crescimento populacional vegetativo - resultante do saldo entre fecundidade e mortalidade, no qual Santo Amaro da Imperatriz apresentou lento progresso, que traria um aumento no tamanho das famílias, sem, necessariamente, uma dispersão na ocupação urbana.

\section{REFERÊNCIAS}

BRENNER, Neil. Espaços da urbanização: o urbano a partir da teoria. 1. ed. Rio de Janeiro: Letra Capital, Observatório das Metrópoles, 2018.

CARLOS, Ana Fani A. A (Re)Produção do Espaço Urbano. 1. ed. São Paulo: Edusp, 1994.

CARMO, Roberto L.; CAMARGO, Kelly C. M. Dinâmica demográfica brasileira recente: padrões regionais de diferenciação. Texto para discussão. Brasília; Rio de Janeiro: IPEA, 2018. Disponível em: file:/ / C:/Users/User/Downloads/td_2415 \%20(1).pdf Acesso em:22jul 2019.

FRANCESCHI, Bruna B.; OLIVEIRA, José Luiz R. Distribuição espacial da precipitação na Bacia Hidrográfica do Rio Cubatão Sul - SC. In: Simpósio Brasileiro de Recursos Hídricos, 22., 2017, Florianópolis. Anais. Florianópolis: Associação Brasileira de Recursos Hídricos, 2017. Disponível em: http:/ / anais.abrh.org.br/ works/2771 Acesso em: 09 dez 2019.

INSTITUTO BRASILEIRO DE GEOGRAFIA E ESTATÍSTICA - IBGE. Estimativa da População 2019. Disponível em: file:///C:/Users/User/Downloads/estimativa_dou_2019.pdf Acesso em: 08 dez 2019.

KAETSU, Patrícia T. A abordagem sistêmica na Gestão Integrada dos Recursos Hídricos: limites e possibilidades de atuação do Comitê Cubatão. 2015. Dissertação (Mestrado em Planejamento Territorial e Desenvolvimento Socioambiental) - Centro de Ciências Humanas e da Educação, Universidade do Estado de Santa Catarina, UDESC, 2015.

LEFEVBRE, Henri. A Revolução Urbana. Belo Horizonte: Editora UFMG, 2004.

LEFEBVRE, Henri. De lo rural a lo urbano. 4. ed. Barcelona: Ediciones Península, 1978. 
PELLERIN, Joel. Contribuição ao estudo de parques: Parque Estadual da Serra do Tabuleiro e Parque Nacional de São Joaquim. Cadernos Geográficos. Florianópolis, n.25, set. 2011, p.01-52.

PREFEITURA MUNICIPAL DE SANTO AMARO DA IMPERATRIZ - PMSAI. Plano Diretor. Disponível em: http:/ / www.santoamaro.sc.gov.br/planodiretor/ Acesso em: 08 dez 2019.

RANGEL, Ignácio. Obras Reunidas. vol. 2. Rio de Janeiro: Contraponto, 2005.

SANTA CATARINA. SECRETARIA DE ESTADO DO DESENVOLVIMENTO ECONÔMICO SUSTENTÁVEL - SDS. Bacias Hidrográficas de Santa Catarina. Gerência de Planejamento de Recursos Hídricos. Florianópolis, 30/04/2018. http://www.aguas.sc.gov.br/jsmallfib _top/DHRI/bacias_hidrograficas/bacias_hidrograficas_sc.pdf. Acesso em:31 jul 2019.

Santo Amaro da Imperatriz -SC. Atlas do Desenvolvimento Humano no Brasil. 2013. Disponível em: http://atlasbrasil.org.br/2013/pt/perfil_m/2400. Acesso em: 17 fev 2019.

SANTOS, Milton. A urbanização brasileira. 1.ed. São Paulo: Hucitec, 1993.

SANTOS, Milton. Espaço \& Método.1. ed. São Paulo: Nobel, 1985.

SILVA, Aline A. da.; SILVA, Everton da.; TEIXEIRA, Kaliu. A dinâmica do Imposto Predial e Territorial Urbano na Região Metropolitana da Grande Florianópolis. In: SIMPÓSIO DE GEOGRAFIA, 18., 2018, Florianópolis. Anais. Florianópolis: UDESC, 2018, v.1, p.327-338. Disponível em: http://www.faed.udesc.br/arquivos/id_submenu/ 3187/anais_simgeo_2018.pdf Acesso em: $06 \operatorname{dez} 2019$.

SINGER, Paul. Economia política da urbanização. 2. ed. São Paulo: Contexto, 2002.

SUGUIO, Kenitiro. BIGARELLA, João J. Ambientes Fluviais. 2. ed. Florianópolis: Editora da UFSC, 1990.

TRIBUNAL DE CONTAS DO ESTADO DE SANTA CATARINA. Informações dos municípios. Esfinge. Disponível em: http:/ / servicos.tce.sc.gov.br/sic/homesic.php Acesso em: 03 jul 2020.

VEADO, Ricardo W. ad-Víncula. Geossistemas de Santa Catarina. In: ROCHA, Isa de O. (org.). Atlas Geográfico de Santa Catarina: diversidade da natureza. Fascículo 2. Florianópolis: SEPLAN/SC, Editora da UDESC, 2014, p.16-44.

\section{INFORMAÇÕES DOS AUTORES}

\section{Karina Martins da Cruz}

Professora da Universidade do Extremo Sul Catarinense. Mestre em Geografia pela Universidade Federal de Santa Catarina e Doutoranda em Planejamento Territorial e Desenvolvimento Socioambiental pela Universidade do Estado de Santa Catarina.

E-mail:karina.cruz@edu.udesc.br

Orcid:https:/ / orcid.org/0000-0002-7519-1484

Lattes: http:/ / lattes.cnpq.br/3933580749963557

\section{Isa de Oliveira Rocha}

Professora Associada do Departamento de Geografia e do Programa de Pós-Graduação em Planejamento Territorial e Desenvolvimento Socioambiental da Universidade do Estado de Santa Catarina. Doutora em Geografia Humana pela Universidade de São Paulo e Pós-Doutora pela Bridgewater State University - Massachusetts. É líder do grupo de pesquisa Natureza e

Sociedade: Autonomia e Relação, e coordenadora do Laboratório de Planejamento Urbano e Regional da Universidade do Estado de Santa Catarina.

E-mail:isa.rocha@udesc.br Orcid:https:/ / orcid.org/0000-0001-9840-0595

Lattes: http:/ / lattes.cnpq.br/1496052603726931 


\section{Márcio Ricardo Teixeira Moreira}

Professor no EBTT do Instituto Federal de Santa Catarina - Câmpus Florianópolis. Doutor em Geografia pela Universidade Federal de Santa Catarina e Pós-Doutorando em Planejamento Territorial e Desenvolvimento Socioambiental pela Universidade do Estado deSanta Catarina.

E-mail:mmoreira@ifsc.edu.br

Orcid: https:/ / orcid.org/0000-0002-9677-9578

Lattes: http:/ / lattes.cnpq.br/0608591188966388

Recebido em: 07/10/2020

Aceito em: 07/04/2021 